\title{
Biomimetic mineralized strontium-doped hydroxyapatite on porous poly(L-lactic acid) scaffolds for bone defect repair
}

This article was published in the following Dove Press journal:

International Journal of Nanomedicine

\author{
Min $\mathrm{Ge}^{1,2}$ \\ Kun $\mathrm{Ge}^{1,3}$ \\ Fei $\mathrm{Gao}^{4}$ \\ Weixiao Yan ${ }^{1,2}$ \\ Huifang Liu² \\ Li Xue \\ Yi Jin ${ }^{1,2}$ \\ Haiyun $\mathrm{Ma}$ \\ Jinchao Zhang ${ }^{1,2}$ \\ 'Department of Chemistry, College \\ of Chemistry and Environmental \\ Science, Hebei University, Baoding, \\ People's Republic of China; ${ }^{2}$ Key \\ Laboratory of Chemical Biology \\ of Hebei Province, Key Laboratory \\ of Medicinal Chemistry and \\ Molecular Diagnosis of the Ministry \\ of Education, Hebei University, \\ Baoding, People's Republic of \\ China; ${ }^{3}$ Department of Science and \\ Technology, Affiliated Hospital of \\ Hebei University, Baoding, People's \\ Republic of China; ${ }^{4}$ Department \\ of Orthopedics, Affiliated Hospital \\ of Hebei University, Baoding, \\ People's Republic of China
}

Introduction: Poly(L-lactic acid) (PLLA) has been approved for clinical use by the US Food and Drug Administration (FDA); however, their stronger hydrophobicity and relatively fast degradation rate restricted their widespread application. In consideration of the composition of bone, the inorganic-organic composite has a great application prospect in bone tissue engineering. Many inorganic-organic composite scaffolds were prepared by directly mixing the active ingredient, but this method is uncontrolled and will lead to lack of homogeneity in the polymer matrix. Strontium $(\mathrm{Sr})$ is an admirable addition to improve the bioactivity and bone induction of hydroxyapatite (HA). To our knowledge, the application of biomimetic mineralized strontiumdoped hydroxyapatite on porous poly(L-lactic acid) (Sr-HA/PLLA) scaffolds for bone defect repair has never been reported till date. Biomimetic mineralized Sr-HA/PLLA porous scaffold was developed in this study. The results indicated that the Sr-HA/PLLA porous scaffold could improve the surface hydrophobicity, reduce the acidic environment of the degradation, and enhance the osteoinductivity; moreover, the ability of protein adsorption and the modulus of compression were increased. The results also clearly showed the effectiveness of the Sr-HA/ PLLA porous scaffold in promoting cell adhesion, proliferation, and alkaline phosphatase (ALP) activity. The micro computed tomography (micro-CT) results showed that more new bones were formed by Sr-HA/PLLA porous scaffold treatment. The histological results confirmed the osteoinductivity of the Sr-HA/PLLA porous scaffold. The results suggested that the Sr-HA/PLLA porous scaffold has a good application prospect in bone tissue engineering in the future.

Purpose: The purpose of this study was to promote the bone repair.

Materials and methods: Surgical operation of rabbits was carried out in this study.

Results: The results showed that formation of a large number of new bones by the Sr-HA/PLLA porous scaffold treatment is possible.

Conclusion: Biomimetic mineralized Sr-HA/PLLA porous scaffold could effectively promote the restoration of bone defects in vivo.

Keywords: Sr-HA, PLLA porous scaffold, biomimetic mineralization, bone repair

\section{Introduction}

Bone defect is a common clinical disease and also a serious problem in the orthopedic treatment. A study showed that there are more than one million patients with bone defect each year in China due to illness and trauma, and the repair of bone defects has always been the focus of continuous research. ${ }^{1}$ To satisfy the different needs in bone tissue engineering, various materials have been employed as scaffolds for tissue reconstruction. Generally, these materials are divided into three groups: metals, ceramics, and polymers. The metals such as titanium (Ti) are the excellent substitute 
for medical implants because of their superior load-bearing properties; however, they lack degradability and osteoconductivity in the body, which limit their applications. ${ }^{2,3}$ Yang et al reported that the surface-modified Ti with hydroxyapatite (HA) and heparin-bone morphogenetic protein-2 complex could enhance the efficiency of bone formation and integration in vivo. ${ }^{3}$ The biological ceramic materials, such as calcium phosphates and HA, for tissue engineering because of the good osteoconductivity are also limited due to brittleness and poor degradability. ${ }^{4,5}$ Polymers have been extensively applied in the bone tissue engineering because of design flexibility and good biodegradability. ${ }^{6,7}$ They can be categorized as natural and synthetic materials according to their composition. The natural materials are difficult to be widely used due to the limited sources. As compared with the natural polymers, the synthetic polymers were favored due to various advantages, including consistent degradation properties, massive production, and being tailored according to specific purpose. Now many synthetic polymers have widespread application in the bone tissue engineering, for example, poly(glycolic acid) (PGA) and poly(caprolactone) (PCL). ${ }^{8,9}$ As an environmentally friendly material, poly(Llactic acid) (PLLA) has been approved for clinical use in humans by the US Food and Drug Administration (FDA). ${ }^{10,11}$ However, PLLA has a strong hydrophobicity and a relatively fast degradation rate; a further widespread application has been considerably restricted.

An ideal bone tissue engineering scaffold should facilitate the growth and activity of cells, such as adhesion, proliferation, and differentiated function. ${ }^{12}$ To act as the extracellular matrix (ECM) for tissue regeneration, many works have been done to modify the PLLA. Alvarez-Barreto et a ${ }^{13}$ manufactured the Arg-Gly-Asp-functionalized PLLA scaffolds to modulate cell behaviors and improve tissue function for more efficient tissue engineering strategies. Ma et al deposited calcium phosphate on the PLLA nanofibrous scaffolds by electrodeposition process. The mineral coating on such scaffolds is similar to the composition of natural bone. ${ }^{14}$ However, these nanofibrous scaffolds were short of osteoinductivity, which is required to be a bone implant material. Considering that the natural bone mainly consists of collagen fibers and apatite crystals, the inorganic-organic composite materials have a great application prospect in bone tissue engineering. Many inorganic--organic composite scaffolds were prepared by directly mixing the active ingredients, ${ }^{15}$ but this mixing method was uncontrolled and led to a lack of homogeneity in the polymer matrix. ${ }^{16}$ The nano-HA has good biocompatibility and bioactivity, which are vital for cell growth. ${ }^{17}$ In addition, it is well known that strontium (Sr) has been proved to enhance the proliferation of osteoblasts, promote the formation of new bone and osseointegration, and prevent infaust bone dissolution. $\mathrm{Sr}^{2+}$ could act on bone via the calcium-sensing receptor and promote the transductions of the mitogen-activated protein kinase signaling. ${ }^{18}$ Therefore, $\mathrm{Sr}$ is an admirable addition to improve the bioactivity and bone induction of HA. ${ }^{19,20}$ In addition, the replacement of $\mathrm{Ca}^{2+}$ with $\mathrm{Sr}^{2+}$ in HA can not only change the discreteness of HA but also greatly improve the growth mechanics of the crystal. ${ }^{21}$ Guo et al developed a Sr-incorporated HA cement, which has many excellent physiochemical properties. ${ }^{22}$ Tian et al prepared a strontium-doped calcium polyphosphate scaffold that showed good biocompatibility, osteogenesis, and degradability. ${ }^{23}$ John et al manufactured strontiumdoped organic-inorganic scaffolds and demonstrated that the scaffolds created a favorable rough topography that was helpful for cellular attachment and growth. ${ }^{24}$ Biomimetic mineralization is another common method to manufacture biopolymer-apatite composite scaffolds. ${ }^{25,26}$ The apatite formation in this natural deposition manner can greatly simulate the inorganic component of bone. The homogeneous apatite on the polymer surface can provide a more biocompatible interface for bone repair. To our knowledge, the application of biomimetic mineralized strontium-doped hydroxyapatite on porous poly(L-lactic acid) (Sr-HA/PLLA) scaffolds for bone defect repair has never been reported till date.

To prepare a Sr-HA/PLLA porous bone repair scaffold with good biocompatibility, osteogenesis, and degradability in an easy controlled condition, the advantages of PLLA, HAP, and $\mathrm{Sr}^{2+}$ were integrated in this study. The biomimetic mineralized Sr-HA was deposited on PLLA porous scaffolds by soaking in modified simulated body fluid (m-SBF) solution. The hydrophobicity, degradation, biocompatibility, and the bone defect repair ability of the Sr-HA/PLLA porous scaffold were studied. Our results indicated that the water contact angle of the Sr-HA/PLLA porous scaffold was decreased from $131.9^{\circ}$ to $37.3^{\circ}$. The microenvironment of degradation of the Sr-HA/PLLA porous scaffold is neutral. In addition, the experiments in vitro and vivo confirmed that the Sr-HA/ PLLA porous scaffold possessed favorable biocompatibility, could increase cell adhesion, and could promote bone repair. This Sr-HA/PLLA porous scaffold may be developed to be applied in the bone tissue engineering in the future.

\section{Materials and methods Materials}

PLLA with an inherent viscosity of $1.6 \mathrm{dL} / \mathrm{g}$ was purchased from Ji'nan Daigang (Ji Nan, China). D-Fructose (melting point [m.p.] $119^{\circ} \mathrm{C}-122^{\circ} \mathrm{C}$ ) and Span 80 were purchased 
from Sigma-Aldrich Co. (St Louis, MO, USA). Dioxane, cyclohexane, and hexane were purchased from SigmaAldrich Co. Fetal bovine serum (FBS), minimum essential medium alpha medium ( $\alpha$-MEM), and trypsin were obtained from Thermo Fisher Scientific (Waltham, MA, USA). Sodium dodecyl sulfate (SDS), dimethyl sulfoxide (DMSO), 3-[4,5-dimetylthiazole-2-yl]-2,5-diphenyltetrazolium bromide (MTT), glutaraldehyde, and bovine serum albumin (BSA) were obtained from Sigma-Aldrich Co. The assay kits of bicinchoninic acid (BCA) protein and alkaline phosphatase (ALP) were purchased from Beyotime Biotechnology (Northern Island, UK). The ActinGreen 488 and the 4'6diamidino-2-phenylindole (DAPI) were purchased from Thermo Fisher Scientific. The mouse preosteoblast cell line (MC3T3-E1) was obtained from China Infrastructure of Cell Line Resource (Beijing, China). ICR mice and JW rabbits were purchased from Vital River Experimental Animal Co. Ltd. (Beijing, China). $\mathrm{NaCl}, \mathrm{KCl}, \mathrm{K}_{2} \mathrm{HPO}_{4} \cdot 3 \mathrm{H}_{2} \mathrm{O}$, $\mathrm{CaCl}_{2} \cdot 2 \mathrm{H}_{2} \mathrm{O}, \mathrm{SrCl}_{2} \cdot 6 \mathrm{H}_{2} \mathrm{O}, \mathrm{MgCl}_{2} \cdot 6 \mathrm{H}_{2} \mathrm{O}, \mathrm{Na}_{2} \mathrm{SO}_{4}$, and $\mathrm{NaHCO}_{3}$ were purchased from Sigma-Aldrich Co. and used without further purification.

\section{Preparation of biomimetic mineralized Sr-HA/PLLA porous scaffold}

The PLLA porous scaffold was fabricated using established procedures. ${ }^{27,28}$ The details are provided in the "Supplementary materials" section. The biomimetic mineralized Sr-HA/PLLA scaffolds were fabricated as follows: $1.5 \times$ m-SBF solution $\left(213 \mathrm{mM} \mathrm{Na}^{+}, 7.5 \mathrm{mM} \mathrm{K}^{+}, 2.3 \mathrm{mM} \mathrm{Mg}^{2+}\right.$, $3.04 \mathrm{mM} \mathrm{Ca}^{2+}, 0.76 \mathrm{mM} \mathrm{Sr}^{2+}, 221.7 \mathrm{mM} \mathrm{Cl}^{-}, 6.3 \mathrm{mM} \mathrm{HCO}^{3-}$, $1.5 \mathrm{mM} \mathrm{HPO}_{4}{ }^{2-}$, and $0.8 \mathrm{mM} \mathrm{SO}_{4}{ }^{2-}$ ) was prepared according to the reported method and stored at $4{ }^{\circ} \mathrm{C} .{ }^{29}$ The PLLA porous scaffolds were incubated in the $1.5 \times \mathrm{m}$-SBF solution (pH 7.4) at $37^{\circ} \mathrm{C}$ for 7 days. After being thoroughly washed with ultrapure water several times, the product was dried by lyophilization.

\section{Characterization of the Sr-HA/PLLA porous scaffold}

The morphology of the Sr-HA/PLLA porous scaffold was observed by scanning electron microscope (SEM; JMS7500F; JEOL, Tokyo, Japan), micro computed tomography (micro-CT; Skyscan; Bruker Optik GmbH, Ettlingen, Germany) at $50 \mathrm{kV}$ and $200 \mu \mathrm{A}$, and transmission electron microscope (TEM; F20 S-TWIN; FEI, Hillsboro, USA). The Sr-HA was characterized by X-ray diffraction (XRD) powder (D8; Bruker Optik $\mathrm{GmbH}$ ) using $\mathrm{Cu} \cdot \mathrm{K} \alpha$ radiation ( $\lambda=0.15405 \mathrm{~nm}$ ), energy-dispersive spectrometer (EDS; ProX; Phenom, Eindhoven, Holland) at $15 \mathrm{kV}$, and Fourier-transform infrared spectroscopy (FTIR) (Tensor 27; Bruker Optik $\mathrm{GmbH})$. The hydrophily was tested by the static contact angle meter (OCA 15EC; DataPhysics, Regensburg, Germany).

\section{Measurement of BSA adsorption in the Sr-HA/PLLA porous scaffold}

The protein adsorption was analyzed using a BCA Protein Assay Kit. The scaffolds were completely wetted in the phosphate-buffered saline (PBS) and then placed in the protein solution. ${ }^{30}$ Then, the scaffolds were incubated in $100 \mu \mathrm{g} / \mathrm{mL}$ BSA solution and $\alpha$-MEM with $10 \%$ FBS for $4 \mathrm{~h}$. After $4 \mathrm{~h}$ incubation, the scaffolds were transferred to the micro tubes. The scaffolds were washed with PBS gently and soaked in $1 \%$ SDS solution for $1 \mathrm{~h}$. The total adsorbed capacity of protein was measured by a BCA Protein Assay Kit using a microplate reader (Molecular Devices LLC, Sunnyvale, CA, USA).

\section{Degradation of the Sr-HA/PLLA porous scaffold}

The degradation of the Sr-HA/PLLA porous scaffold was observed by monitoring the $\mathrm{pH}$ value and the mass change in the scaffolds after immersion in PBS. At the time intervals of 10 days, the scaffolds were taken out from PBS, freeze-dried, and weighted. The degradation of composite porous scaffolds was observed using SEM (ProX), and the change in $\mathrm{pH}$ was detected by the $\mathrm{pH}$ meter (E-301F; Lei-ci, Shanghai, China). The mass loss was calculated by using the following equation:

$$
\operatorname{Mass} \operatorname{loss}(\%)=\frac{M_{0}-M_{d}}{M_{0}} \times 100
$$

where $M_{0}$ is the original mass of the scaffolds and $M_{d}$ is the mass of the scaffolds after biodegradation.

\section{Cell culture and seeding}

MC3T3-E1 cells were cultured according to those published by Quarles et al. ${ }^{31}$ For cell seeding, first, the PLLA, hydroxyapatite on porous poly(L-lactic acid) (HA/PLLA), and Sr-HA/ PLLA porous scaffolds were immersed in ethanol for $1 \mathrm{~h}$ and then washed with PBS three times. Then, $2 \times 10^{4}$ cells were cultured in each scaffold.

\section{Cellular morphology}

For SEM observation, after being cultured for 1, 3, and 7 days, the cells were fixed with $2.5 \%$ glutaraldehyde for $4 \mathrm{~h}$. The dehydrated specimens were observed by SEM. After the cells were cultured for 5 days, the nuclei and the actin cytoskeleton were stained with DAPI and ActinGreen 
488 and observed using a fluorescence microscope (EVOS; Thermo Fisher Scientific).

\section{Cell viability assay}

The MC3T3-E1 cells were cultured in the Sr-HA/PLLA scaffolds; the cells without scaffolds were set as the control group. The detailed procedure is reported in our previous study. ${ }^{27}$

\section{ALP assay}

The ALP activity of the MC3T3-E1 cells was analyzed according to our previous work. ${ }^{32}$ In brief, after being cultured for 7 days, the cell scaffolds were homogenized in $100 \mu \mathrm{L}$ of RIPA cell lysis solution. The supernatants were used in ALP activity and protein content measurement according to the routine method described in the ALP activity kit and BCA protein assay kit.

\section{Animal experiment}

All experiments were performed in compliance with the animal management regulations of the Animal Welfare and Ethical Committee of Hebei University and approved by the local ethics committee of Animal Welfare and Ethical Committee of Hebei University. All animals used in the experiment were fed in standard animal facility. The Sr-HA/PLLA porous scaffold was implanted subcutaneously into ICR mice to evaluate the biocompatibility. ${ }^{33}$ The details are provided in the "Supplementary materials" section. The PLLA, HA/PLLA, and Sr-HA/PLLA porous scaffolds were implanted into the defect in four JW rabbits to evaluate the bone repair ability of these scaffolds. First, defects with a diameter of $3.5 \mathrm{~mm}$ were created in the femur of each rabbit using an orthopedic drill. Then, the PLLA, HA/PLLA, and Sr-HA/PLLA scaffolds were implanted by press fitting in the front three defects. Finally, the skin was sutured after complete hemostasis. The rabbits were injected with penicillin for 3 days after surgery to prevent infection. After 5 weeks of implantation, the femurs were removed and the bone repair was evaluated using micro-CT at $70 \mathrm{kV}$ and $80 \mu \mathrm{A}$. Hematoxylin and eosin (H\&E) and Masson stainings of the femoral defect areas were performed. The samples were observed under an optical microscope (BX-53; Olympus Corporation, Tokyo, Japan).

\section{Statistical analysis}

All data were from three separate experiments and presented as the mean \pm standard deviation. The statistical difference was measured by a one-way analysis of variance (ANOVA), followed by Newman-Keuls analysis. $P<0.05$ was considered as statistically significant.

\section{Results and discussion Morphology of Sr-HA/PLLA porous scaffold}

Many methods have been used to coat HA on the polymer materials, including sol-gel technology, ${ }^{34}$ hydrothermal process,${ }^{35}$ precipitation method, ${ }^{36}$ and plasma-sprayed coating. ${ }^{37}$ Beyond this, biomimetic mineralization as another efficient way for preparing the HA coating can mimic the biologically mineralized growth. The formative HA in this process is similar to the mineral in bone. ${ }^{38}$ The earlier study demonstrated that Sr-doped HA exhibited greater bone response properties than a pure HA. ${ }^{39,40}$ The biomimetic mineralized Sr-HA/PLLA porous scaffolds in this work avoided the organic reagent used in the synthesis; the forming process is more natural. The use of biomimetic mineralized Sr-HA on the surface of PLLA porous scaffolds under physiological conditions is a more rapid and simple method to emerge exquisite crystal morphology for cell growth. ${ }^{41}$ SEM and Micro-CT were utilized to analyze the morphology and microstructure of the porous scaffolds after biomimetic mineralization. Figure 1A-F shows the surface morphology of porous scaffolds after mineralization for 7 days. The Sr-HA/ PLLA porous scaffold surface was decorated with uniformly nanoparticles of $\sim 100 \mathrm{~nm}$ diameter (Figure $1 \mathrm{C}$ and $\mathrm{F}$ ). The Sr-HA/PLLA porous scaffold fabricated in $\mathrm{m}-\mathrm{SBF}$ is highly porous and interconnected. As observed from micro-CT (Figure 1G-L), all scaffolds exhibited a highly open-porous structure, and the large pores were interconnected to each. The porous scaffolds are the most promising materials for bone defect repair. Previous works indicated that the porous structures of scaffolds benefited the transmission of nutrients and the ingrowth of tissue.$^{42}$ In addition, nano-scale structures on the porous scaffolds could dramatically promote cell adhesion, differentiation, and tissue growth. ${ }^{43,44}$

\section{Composition analysis of Sr-HA/PLLA porous scaffold}

The chemical composition was demonstrated by FTIR (Figure 2A). There were typical peaks of HA observed from the HA/PLLA and Sr-HA/PLLA porous scaffolds. The $\mathrm{O}-\mathrm{H}$ stretching vibrations appeared at $3,450 \mathrm{~cm}^{-1}$; the bending and stretching vibration of $\mathrm{PO}^{3-}$ bands appeared at $567,627,873,1,042$, and $1,138 \mathrm{~cm}^{-1} .^{29,45}$ The peaks at $1,394,1,640$, and $1,760 \mathrm{~cm}^{-1}$ corresponded to $\mathrm{C}-\mathrm{OH}, \mathrm{C}-\mathrm{C}$, 

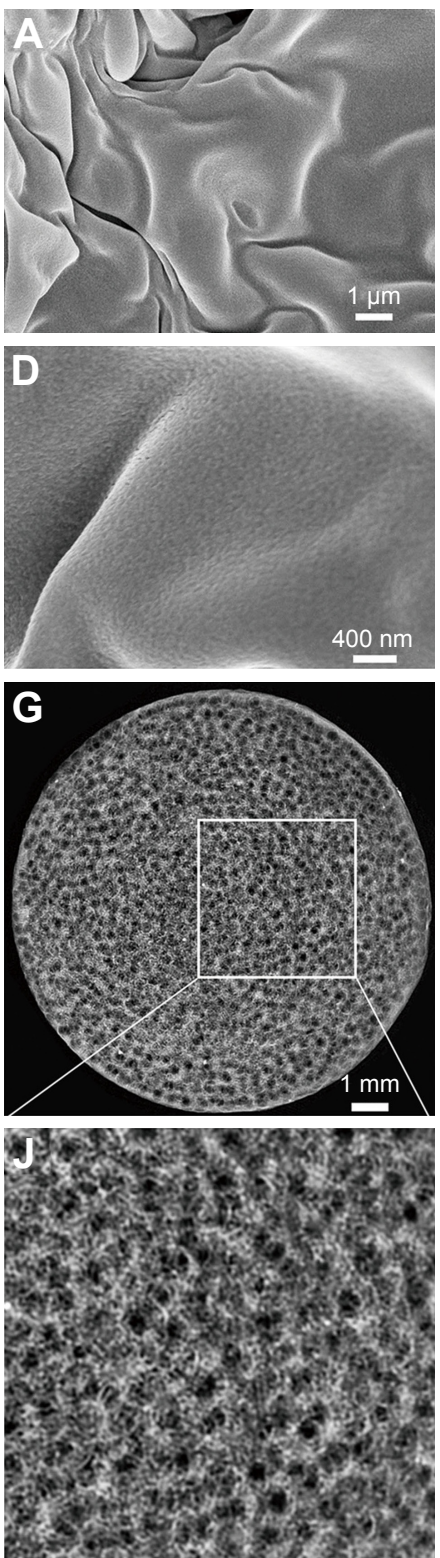
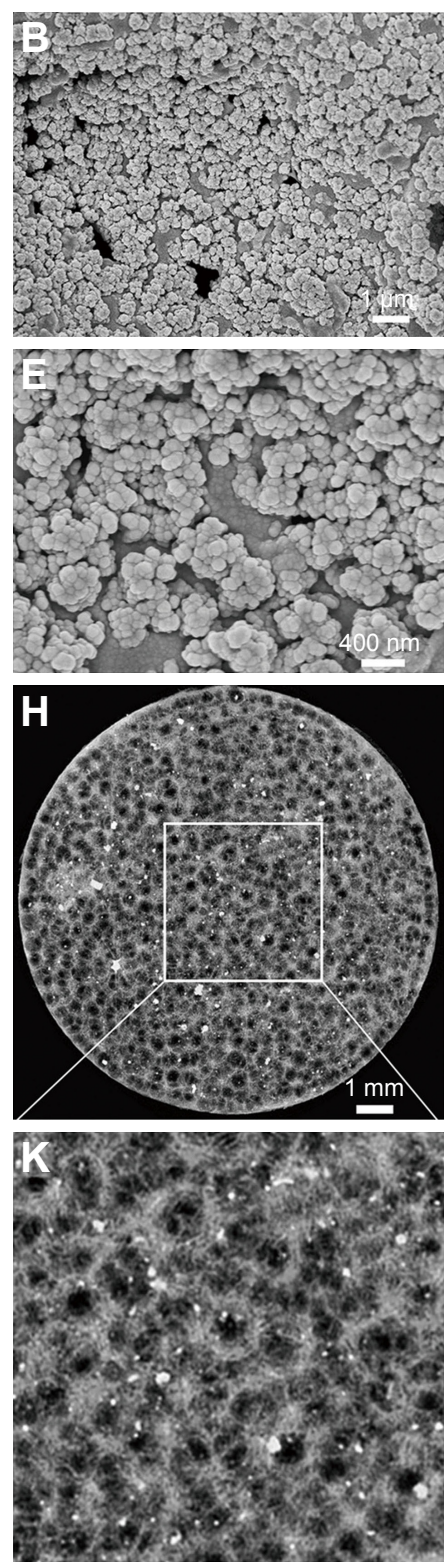
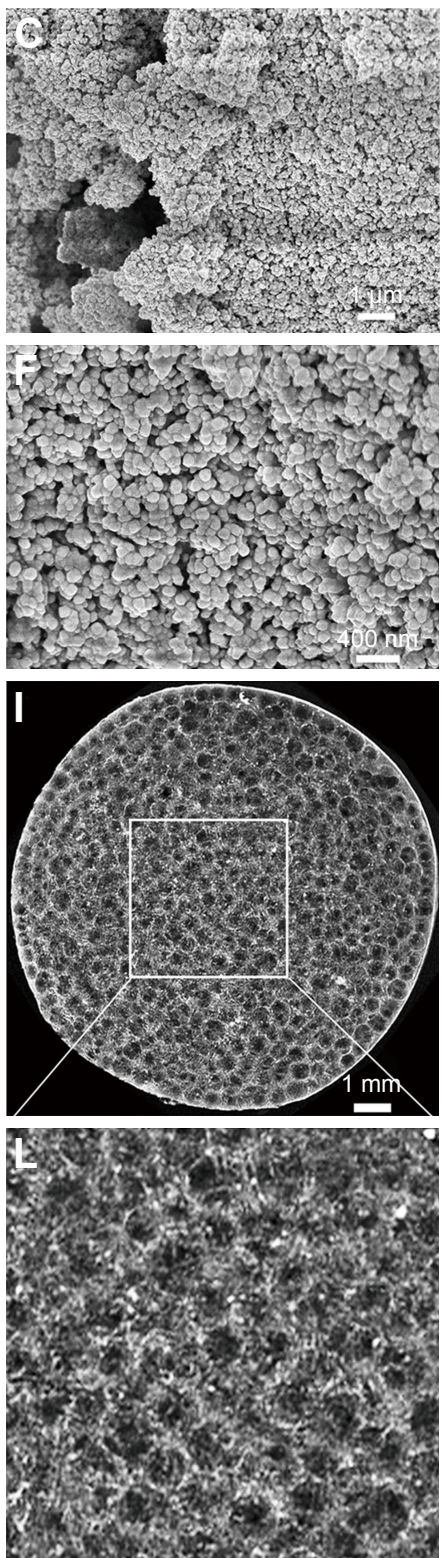

Figure I SEM and micro-CT images of porous scaffolds.

Notes: SEM images of porous scaffolds: PLLA (A and D), HA/PLLA (B and E), and Sr-HA/PLLA (C and F). Micro-CT images of porous scaffolds: PLLA (G and J), HA/PLLA ( $\mathbf{H}$ and $\mathbf{K})$, and Sr-HA/PLLA ( $\mathbf{I}$ and $\mathbf{L})$. Images $\mathbf{J}, \mathbf{K}$, and $\mathbf{L}$ are $\times 2.7$ magnified images of $\mathbf{G}, \mathbf{H}$ and $\mathbf{I}$, respectively.

Abbreviations: SEM, scanning electron microscope; micro-CT, micro computed tomography; PLLA, poly(L-lactic acid); HA/PLLA, hydroxyapatite on porous poly(L-lactic acid); Sr-HA/PLLA, strontium-doped hydroxyapatite on porous poly(L-lactic acid).

and $\mathrm{C}-\mathrm{O}$ stretching vibrations, respectively, which confirm the presence of the covalent linkage of the PLLA. ${ }^{46}$

The structural phase of the deposited minerals was monitored by XRD (Figure 2B). The diffraction peaks can be attributed to pure HA (JCPDS No 76-0694) and Sr-HA (JCPD No 33-1348). The characteristic peaks at 26.1, 31.9, $32.1,34.2,39.9,45.6$, and $49.7^{\circ}$ corresponded to the $\left(\begin{array}{lll}0 & 0 & 2\end{array}\right)$,

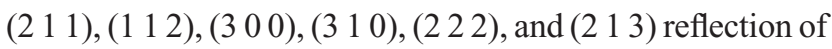
the HA hexagonal phase (JCPDS card, 09-0432). ${ }^{47}$ The main crystalline peaks at $27.4,31.5,32.5,34.8,40.5,45.4$, and 49.9

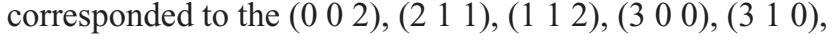
(2 2 (2 2 ), and (2 113 ) reflection of Sr-HA (JCPDS card, 33-1348). ${ }^{48}$ The broad XRD peaks are attributed to the very small size of the particle, which is demonstrated by SEM (Figure 1E and F).

The $\mathrm{Ca} / \mathrm{P}$ atomic ratio of the mineral on the PLLA porous scaffold was analyzed by EDS. As shown in Figure 2C and D, significant calcium, phosphorous, and strontium peaks were observed. The molar ratio of $\mathrm{Ca} / \mathrm{P}$ of the composite is 1.54 , which is consistent with the biological apatite. ${ }^{49}$ The TEM 

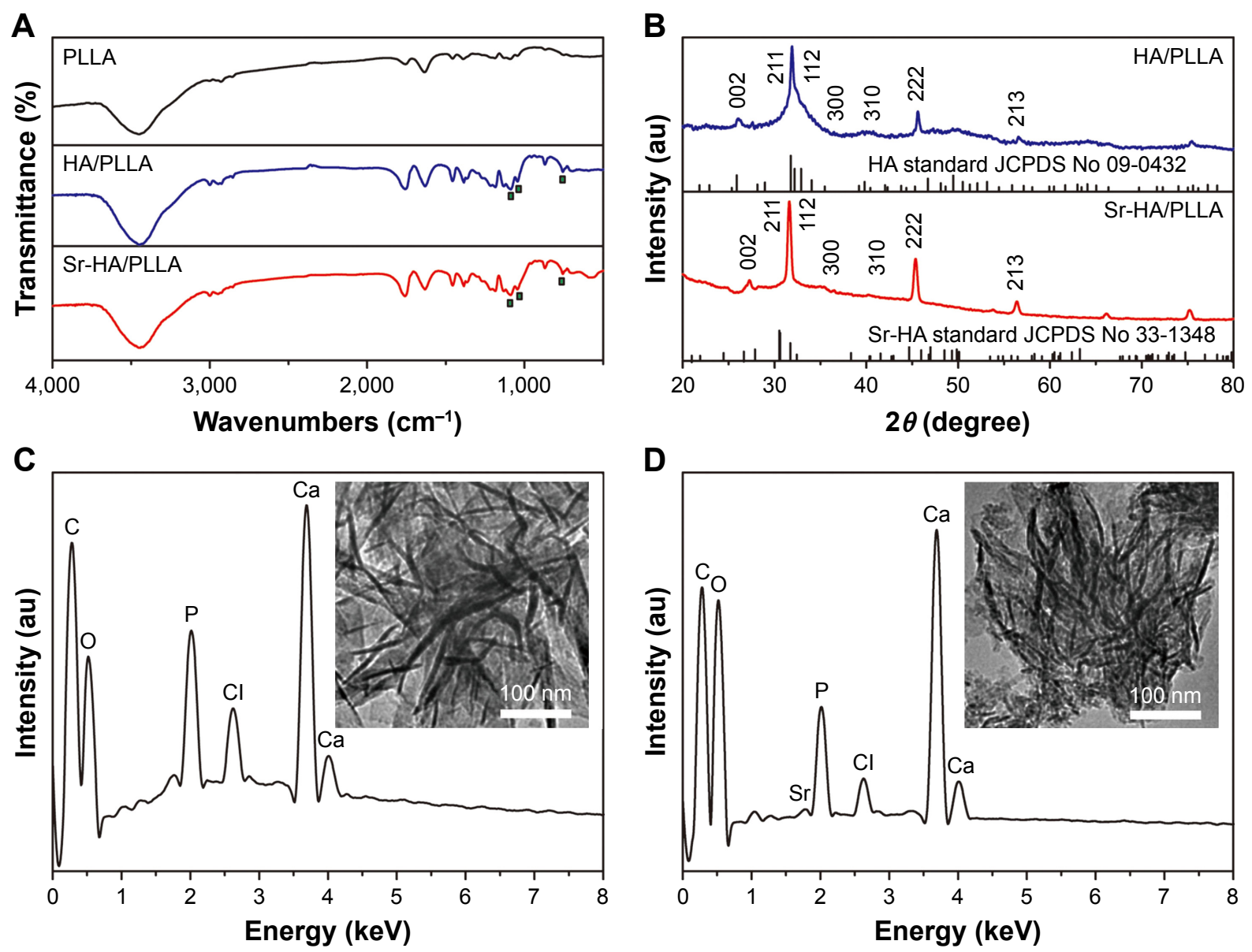

Figure 2 The FTIR, XRD patterns, and EDS of different porous scaffolds.

Notes: (A) FTIR spectra of porous scaffolds. (B) XRD patterns of porous scaffolds. (C) EDS of the HA on the HA/PLLA porous scaffolds. (D) EDS of the Sr-HA on the Sr-HA/PLLA porous scaffolds.

Abbreviations: FTIR, Fourier-transform infrared spectroscopy; XRD, X-ray diffraction; EDS, energy-dispersive spectrometer; HA, hydroxyapatite; HA/PLLA, hydroxyapatite on porous poly(L-lactic acid); Sr-HA, strontium-doped hydroxyapatite; Sr-HA/PLLA, strontium-doped hydroxyapatite on porous poly(L-lactic acid); au, atomic unit.

images (insets in Figure 2C and D) of the crystals showed typical needle-like crystals.

\section{Properties of Sr-HA/PLLA porous scaffold}

The cell adhesion to the surface of material is closely related to their chemical properties such as hydrophilicity, mechanical strength, and degradability. The hydrophilic scaffold allows for fast adhesion of cells and high-efficient cell seeding. ${ }^{50}$ Ma et $\mathrm{a}^{51}$ revealed that the surfaces of the hydrophilic PLLA notably increased the cell adhesion, meanwhile osteoblasts on hydrophilic surfaces showed enhanced mineralized area. The surface wettability of porous scaffolds was analyzed by the water contact angle. As shown in Figure 3A, water contact angles on PLLA, HA/PLLA, and Sr-HA/PLLA scaffolds were $131.90^{\circ}, 70.27^{\circ}$, and $37.33^{\circ}$ respectively. It can be seen that contact angle values of Sr-HA/PLLA were lower than those of PLLA and HA/PLLA scaffolds, indicating to be more hydrophilic; moreover, the water contact angle values obviously decreased with the doping $\mathrm{Sr}$ in the HA. The Sr-HA/PLLA porous scaffold creates a hydrophilic microenvironment and is beneficial to protein adhesion, which may be more easily stretched for cells under this condition.

In the bone tissue engineering, mechanical property is the main issue faced by the scaffolds for repairing bone. ${ }^{52}$ The mechanical property of the scaffolds is also a challenge. ${ }^{53}$ Liu et al increased the stiffness of electrospinning scaffolds by surface mineralization. ${ }^{54}$ The mechanical properties of the microenvironment are also important for cell growth. ${ }^{55}$ Figure $3 \mathrm{~B}$ characterizes the mechanical properties of the porous scaffolds. The stress-strain curves display a typical elastomeric porous scaffold showing three remarkable features. As can be seen from the results, the Sr-HA/PLLA scaffolds are hard and the compressive modulus is high compared with those of PLLA and HA/PLLA. The Sr-HA/PLLA porous scaffolds will approximate the stiffness of surrounding bones, which are more close to the femur strength $(6.8 \pm 4.8 \mathrm{MPa}){ }^{56}$ 

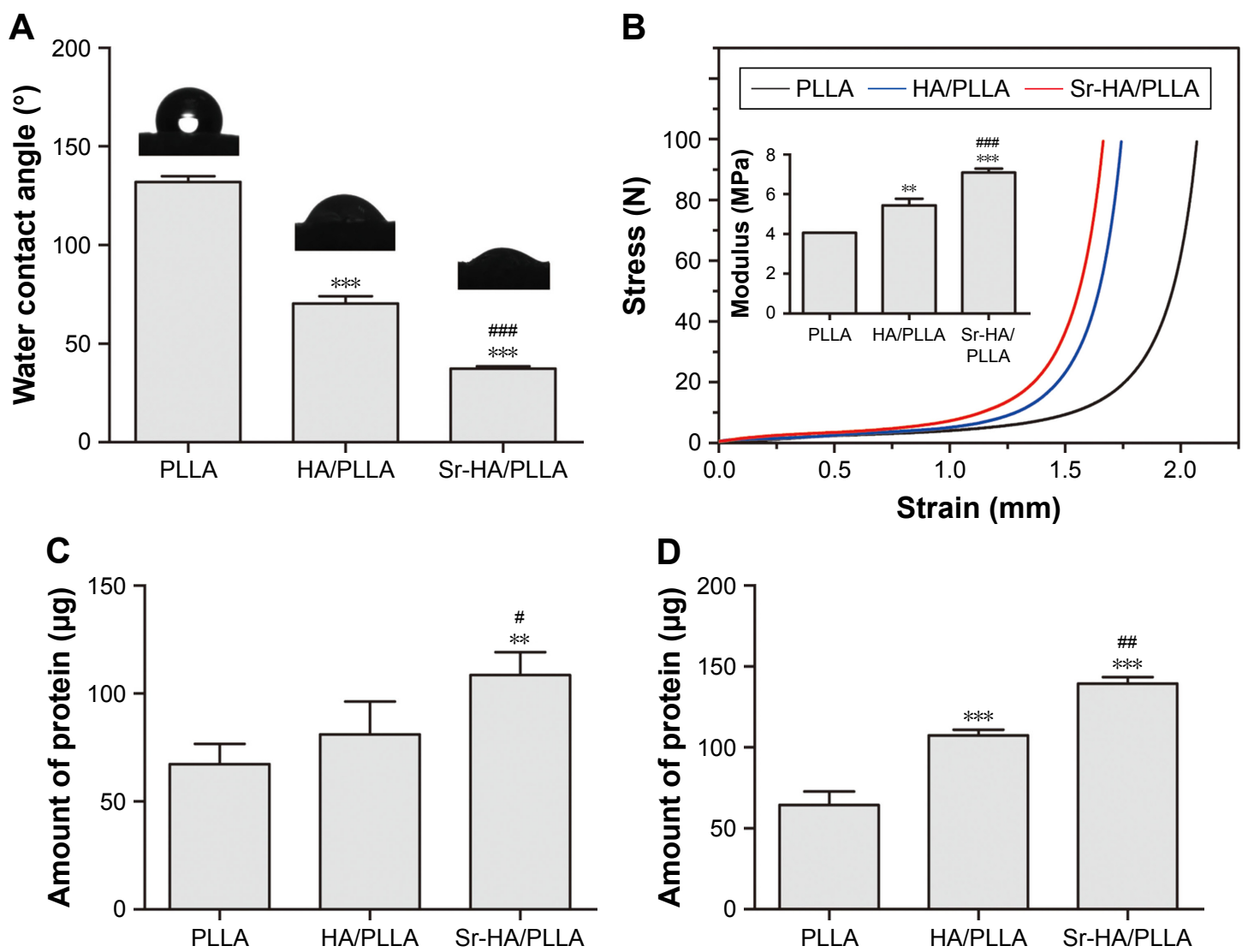

Figure 3 The water contact angle, stress strain, and protein absorption of different porous scaffolds.

Notes: (A) Water contact angle of porous scaffolds. (B) Stress strain of porous scaffolds; inset in (B) represents the compressive modulus of porous scaffolds. (C) The amounts of absorbed protein of porous scaffolds in the 10\% BSA. (D) The amounts of absorbed protein of porous scaffolds in the $\alpha$-MEM with $10 \%$ FBS. $* * P<0.0$, ****P $<0.001$ vs PLLA, ${ }^{\# P}<0.05,{ }^{\# P}<0.01$, and ${ }^{\# P} P=0.001$ indicated as Sr-HA/PLLA vs HA/PLLA.

Abbreviations: BSA, bovine serum albumin; $\alpha$-MEM, minimum essential medium alpha medium; FBS, fetal bovine serum; PLLA, poly(L-lactic acid); Sr-HA/PLLA, strontiumdoped hydroxyapatite on porous poly(L-lactic acid); HA/PLLA, hydroxyapatite on porous poly(L-lactic acid).

It is very well known that protein adsorption on the scaffold surfaces is the primary event when the materials contact with the biological environment as it largely influences the subsequent biological response. ${ }^{57}$ The adsorption capacity on porous scaffolds was limited to the physical and chemical properties of the porous scaffolds. The $10 \%$ BSA solution and $\alpha$-MEM with $10 \%$ FBS were used to test the adsorption capacity of protein. As shown in Figure $3 \mathrm{C}$ and D, the amounts of absorbed protein were obviously different on the porous scaffolds; the Sr-HA/PLLA porous scaffold showed significantly more protein adsorption than the HA/PLLA and Sr-HA/PLLA scaffolds whether in the BSA solution or in the $\alpha$-MEM with $10 \%$ FBS.

An ideal tissue engineering scaffold should be degraded after being implanted into the body. As reported, although the PLLA as scaffolds shows a fast biodegradation rate in the tissue engineering, ${ }^{58}$ the degradation of PLLA in the body will form the acidic environment that will result in adverse inflammatory responses. ${ }^{59}$ As shown in Figure $4 \mathrm{~A}$ and $\mathrm{B}$, the
Sr-HA/PLLA porous scaffold displayed stable morphology and the weight loss was $\sim 40 \%$ after 100 days, which showed slower degradation rate compared with that of the PLLA scaffold $(60 \%)$. The morphology of the Sr-HA/PLLA porous scaffold changed with the increase in immersion time. At day 60, the Sr-HA/PLLA scaffold occurred outbreak, but there were still apparent pore structure. As shown in Figure 4C, the $\mathrm{pH}$ value of PBS solution of the Sr-HA/ PLLA porous scaffold remained to be relatively stable at 7.4 throughout degradation of 100 days. Not surprisingly, the $\mathrm{pH}$ value of PBS solution of PLLA was rapidly reduced from 7.1 to 4.4 due to the acidic product from the degradation of PLLA. This might illustrate that the presence of Sr-HA mitigated the acid due to the degradation of PLLA and hindered the PLLA degradation process.

\section{Morphology of cells in the scaffolds}

A series of PLLA scaffolds have been used in the tissue engineering, such as poly(ether urethane)/poly(L-lactide) 
A
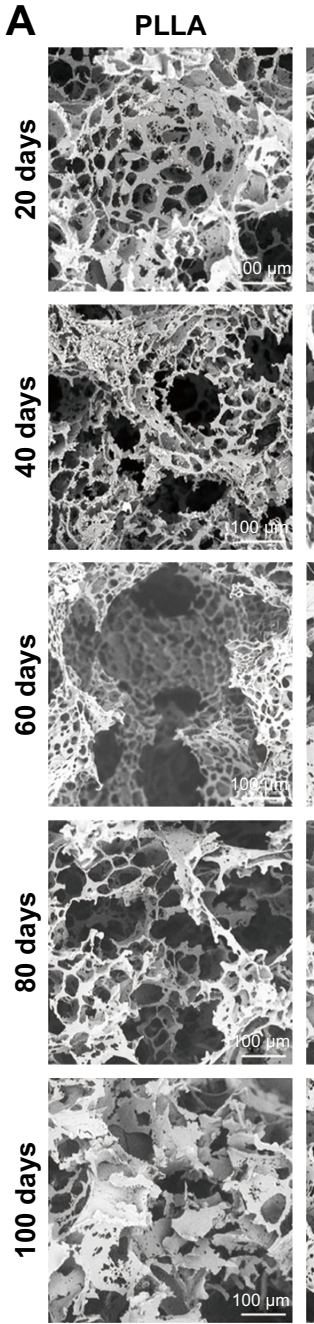

HA/PLLA
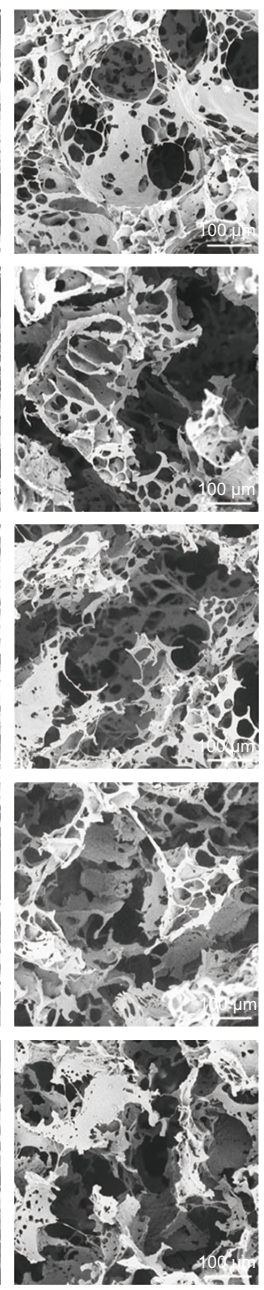

Sr-HA/PLLA
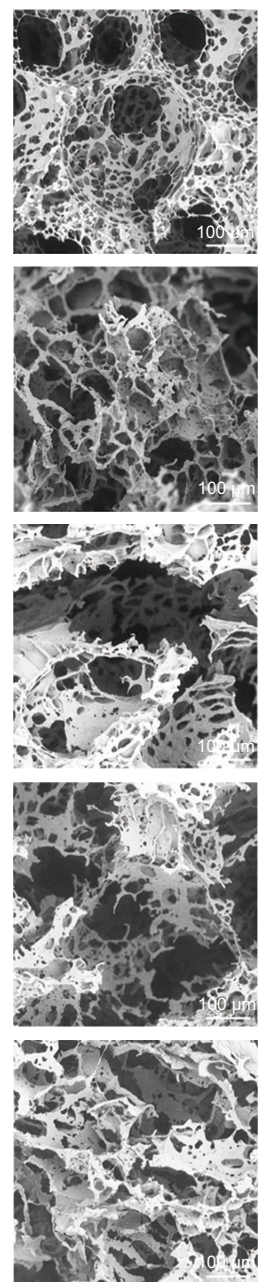
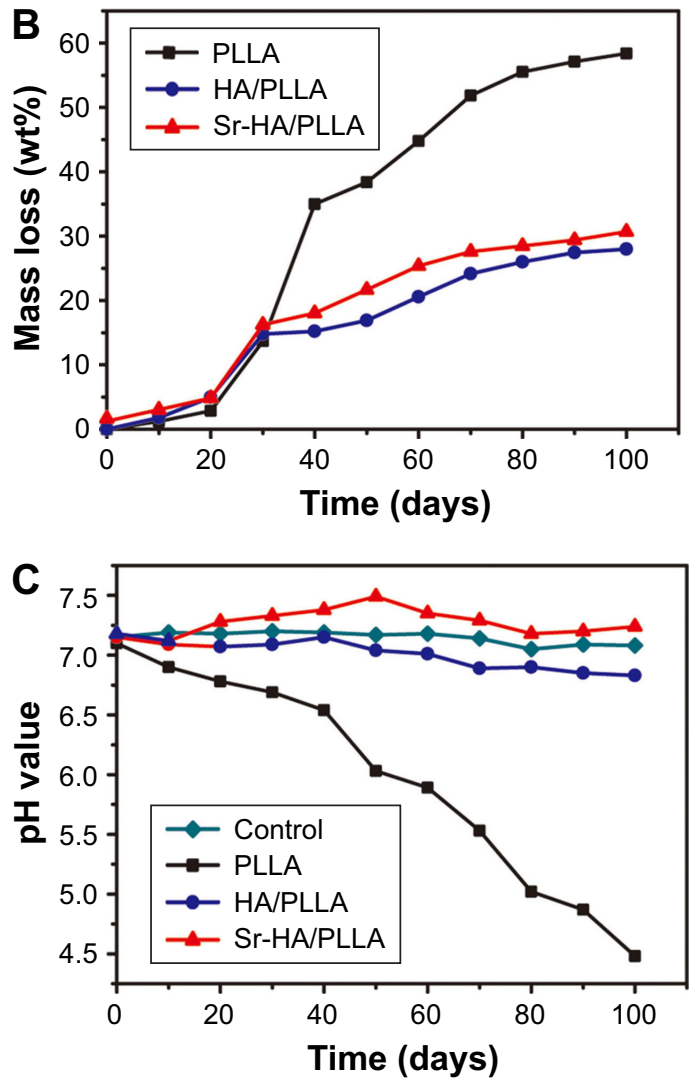

Figure 4 The degradation behavior of different porous scaffolds.

Notes: SEM images $(\mathbf{A})$ and mass loss $(\mathbf{B})$ of different porous scaffolds after immerging in PBS at time intervals. (C) The $\mathrm{pH}$ value changes in PBS after degradation of porous scaffolds at different time points. Magnification $\times 500$.

Abbreviations: SEM, scanning electron microscope; PBS, phosphate buffer solution; PLLA, poly(L-lactic acid); HA/PLLA, hydroxyapatite on porous poly(L-lactic acid); Sr-HA/PLLA, strontium-doped hydroxyapatite on porous poly(L-lactic acid).

(PU/PLLA) used for intestine submucosa repair. Tomecka et $\mathrm{l}^{60}$ reported that PU/PLLA nanofiber was a good substrate for cardiac cell culture and could influence the cell organization and orientation. However, the PU/PLLA scaffold could not be absorbed easily and then cause infection. ${ }^{61}$ The Sr-HA/PLLA scaffold would be another choice to support the cell growth. First, osteoblasts would adhere to the scaffolds, and then the cells would began to proliferate or perform their capability with the scaffolds or themselves. Figure 3 shows that the Sr-HA/PLLA scaffold was hydrophilic, which could favor cell adhesion. The osteoblasts could experience morphological changes to accommodate the interface of cells and materials in the process of the osteoblast differentiation. HA could promote the osteoblasts' adhesion and attachment because of its biological activity and natural affinity with osteoblasts. ${ }^{62}$ The morphology of MC3T3-E1 cells in the porous scaffolds after 1, 3, and 7 days was observed by SEM (Figure 5A). For the cells' adhesion, at day 1, the cells showed a well-spread morphology and maintained normal phenotype in the HA/PLLA and Sr-HA/PLLA porous scaffolds but showed contractiveness in the PLLA scaffold. For the cells' attachment, at day 3, cells in the HA/PLLA and Sr-HA/PLLA porous scaffolds began to migrate to the pore of the scaffolds. At day 7, cells on Sr-HA/PLLA porous scaffolds appeared to be confluent, indicating a superb cell attachment and a stronger interaction with scaffolds.

The growth of MC3T3-E1 cells in the porous scaffolds was further observed by fluorescence microscopy (Figure 5A). At day 5, there was a higher density of cells in Sr-HA/PLLA porous scaffolds compared with the other porous scaffolds. The exposure of Sr-HA nanoparticles on the surface of the 

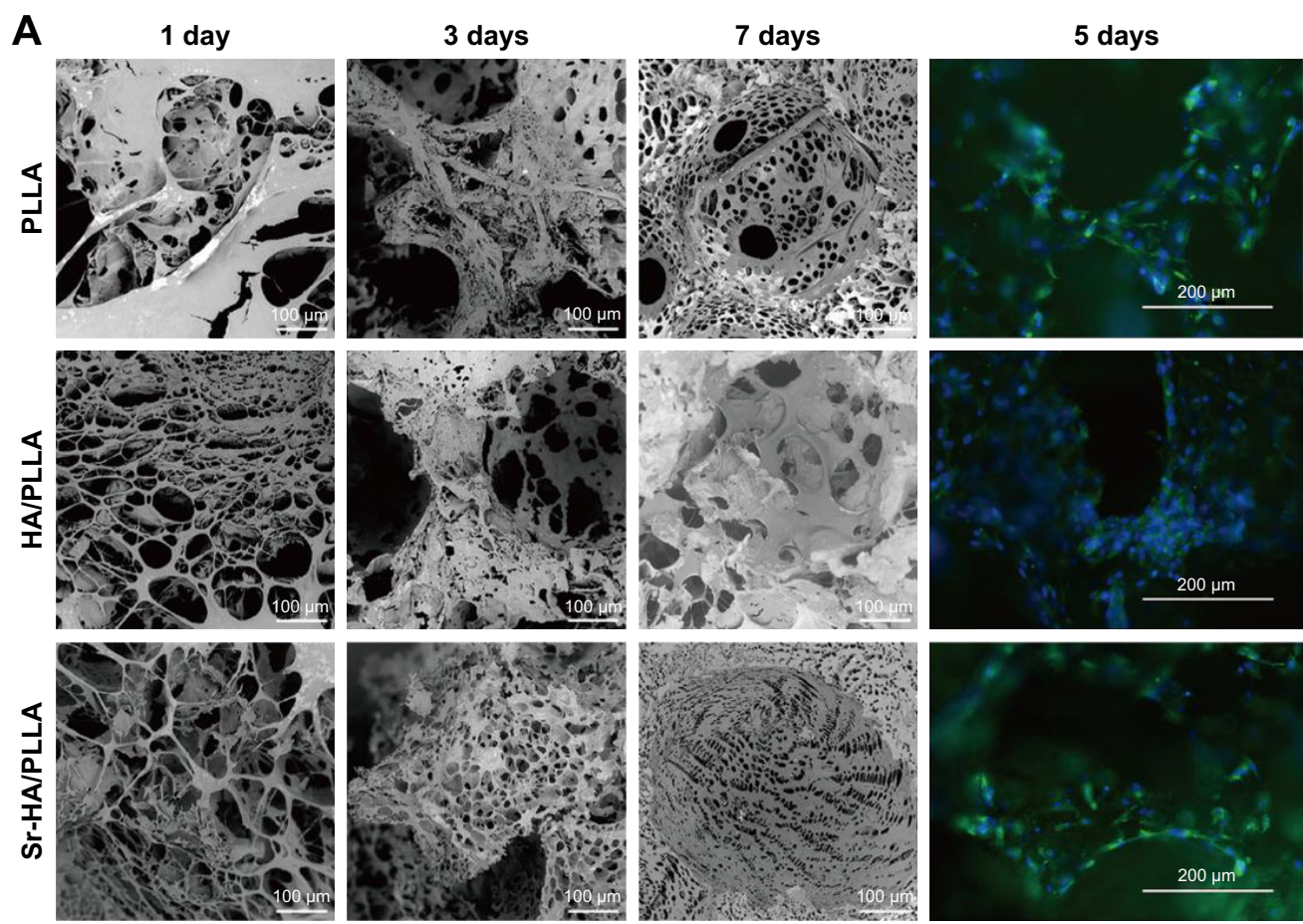

B

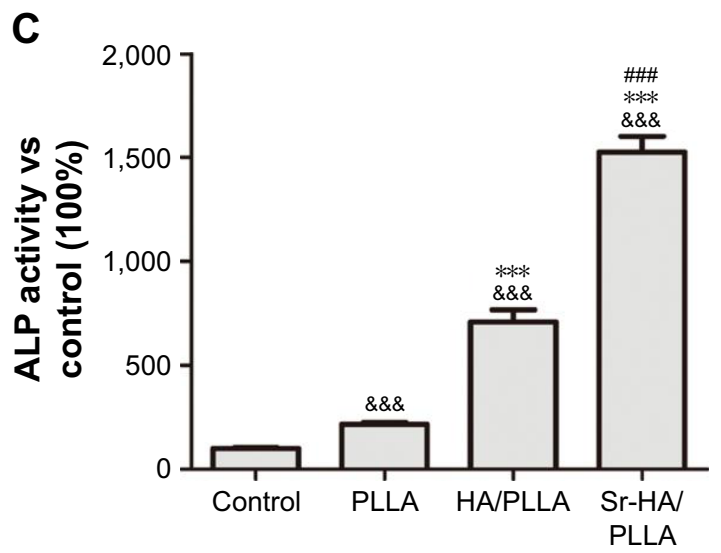

Figure 5 The effects of porous scaffolds on viability and differentiation of MC3T3-EI cells.

Notes: (A) SEM images and fluorescence microscope images of the MC3T3-EI cells cultured on the porous scaffolds for I, 3, 5, and 7 days. (B) The cell viability of MC3T3-E I cells cultured on porous scaffolds for $24 \mathrm{~h}$. (C) ALP activity of the MC3T3-El cells cultured on the porous scaffolds for 7 days. ${ }^{2 \& \& P}<0.00 \mathrm{I}$ vs control, $* * * P<0.00 \mathrm{I}$ indicated as HA/PLLA and Sr-HA/PLLA vs PLLA, and $\quad 0.00$ I indicated as Sr-HA/PLLA vs HA/PLLA. The magnification is 500x.

Abbreviations: SEM, scanning electron microscope; MC3T3-EI, mouse preosteoblast cell line; ALP, alkaline phosphatase; HA/PLLA, hydroxyapatite on porous poly(L-lactic acid); Sr-HA/PLLA, strontium-doped hydroxyapatite on porous poly(L-lactic acid); PLLA, poly(L-lactic acid).

scaffolds had more advantages for cell proliferation. ${ }^{63}$ The cell viability in porous scaffolds indicates that the Sr-HA/ PLLA porous scaffold is beneficial for cell proliferation (Figure 5B).

\section{ALP activity analysis}

ALP is an early marker of osteogenesis differentiation, and the increase in the ALP activity indicates stronger cell-cell and cell-matrix interaction in the three-dimensional space. ${ }^{64,65}$ Figure 5C shows the ALP activity of the MC3T3-E1 cells on the porous scaffolds. At 7 days, the ALP activity of the MC3T3-E1 cells in Sr-HA/PLLA porous scaffolds was sevenfold and twofold higher than that of the MC3T3-E1 cells in the PLLA and HA/PLLA porous scaffolds, respectively. The results suggested that the existence of Sr enhanced the ALP activity of the MC3T3-E1 cells in the porous scaffold.

\section{Biocompatibility analysis in vivo}

The biocompatibility of the scaffolds is one of the essential elements. The Sr-HA/PLLA porous scaffold showed favorable biocompatibility in vivo; the results showed that no damage to the heart, liver, spleen, lung, and kidney was induced by the Sr-HA/PLLA porous scaffold (Figure S1). In addition, the results also showed no obvious inflammatory response 
A

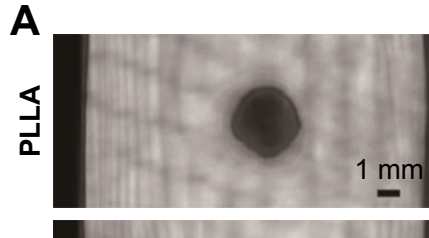

1
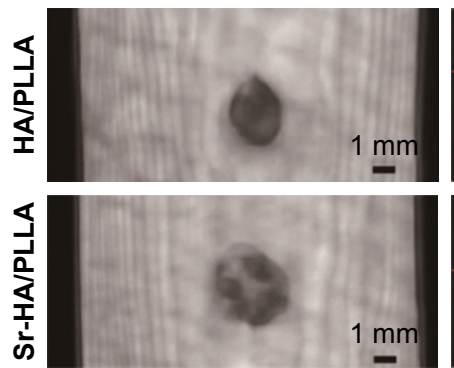
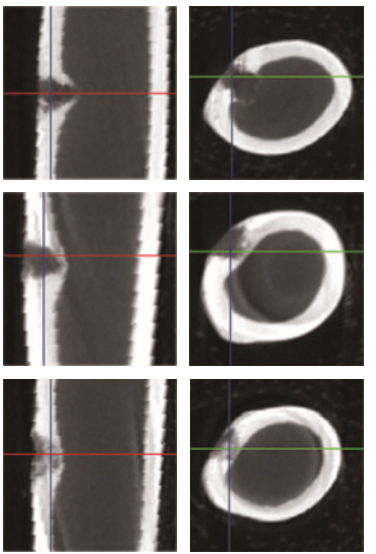

B

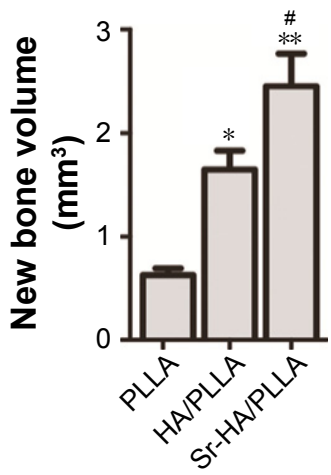

Figure 6 Micro-CT images and new bone volume of femur defects after 4 weeks' implantation of different porous scaffolds in rabbits.

Notes: (A) Micro-CT images of femur defects at 5 weeks after surgery. (B) New bone volume in the defects sites. $* * P<0.0$ I, $* P<0.05$ vs PLLA, and $\# P<0.05$ indicated as Sr-HA/PLLA vs HA/PLLA.

Abbreviations: micro-CT, micro computed tomography; PLLA, poly(L-lactic acid); Sr-HA/PLLA, strontium-doped hydroxyapatite on porous poly(L-lactic acid); HA/PLLA, hydroxyapatite on porous poly(L-lactic acid).

in the Sr-HA/PLLA scaffold after 4 weeks of subcutaneous implantation (Figure S2).

\section{New bone formation analysis}

It was reported that the nano-HA/PLLA materials alone could not effectively repair the bone defect. ${ }^{66}$ However, a critical size defect can be repaired when a little osteoinductive element was added. ${ }^{67}$ Sr-containing scaffolds induced the formation of new bones. ${ }^{68}$ After 5 weeks of surgery, the micro-CT results displayed that a substantial amount of new bones were formed and evenly distributed in the bone defect area by the Sr-HA/PLLA scaffold treatment (Figure 6A), but no new bone formation was observed by the PLLA scaffold treatment. Obviously, the volume of new bones is more in the defects by treatment with Sr-HA/PLLA scaffolds than with the HA/PLLA scaffolds (Figure 6B).

The HE and Masson stain results showed a high level of immature bone and collagen formation in the bone defect area by the Sr-HA/PLLA porous scaffold treatment (Figure 7), while the PLLA scaffold treatment had no significant effect. This may be due to the lack of osteoinductivity for the PLLA porous scaffold, while the biomimetic mineralized Sr-HA/PLLA porous scaffold possessed homogeneous Sr-HA similar to bone-like apatite, which may supply preferable osteoconductivity in the bone tissue engineering. ${ }^{69}$ We deduced that $\mathrm{Sr}$ iron released from $\mathrm{Sr}-\mathrm{HA}$ during the degradation of Sr-HA/PLLA porous scaffolds might promote new bone formation. In addition, some blood vessels were
A

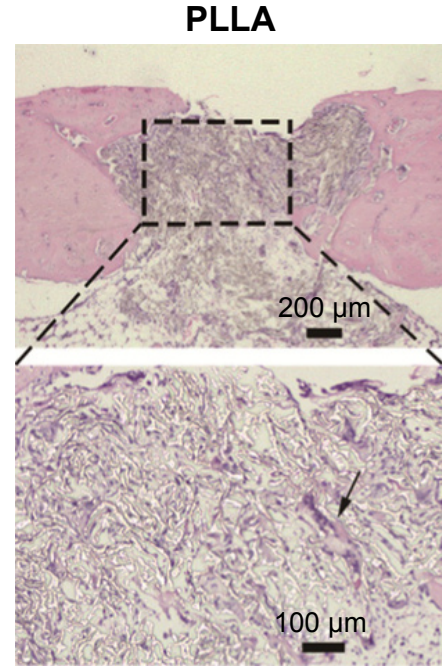

HA/PLLA

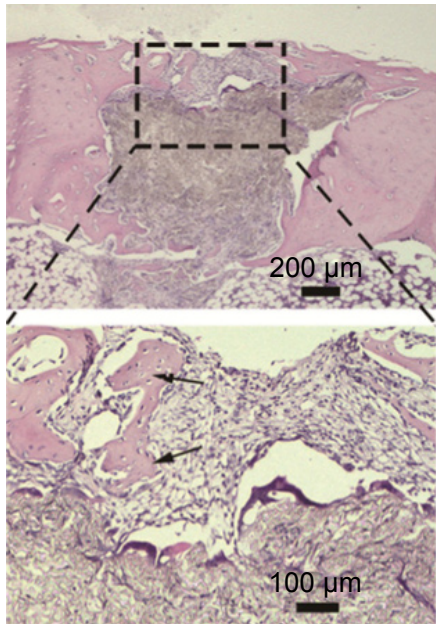

Sr-HA/PLLA

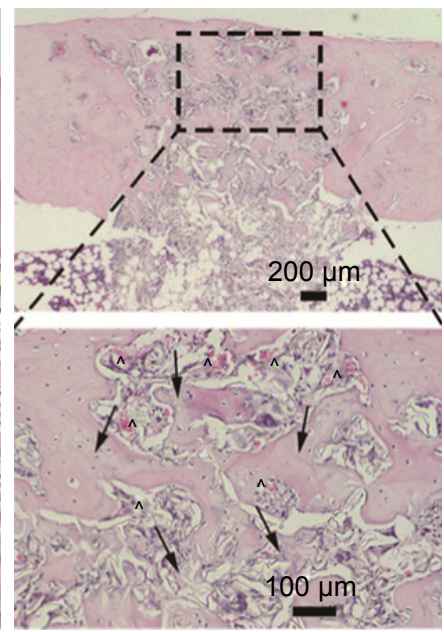

Figure 7 (Continued) 
B

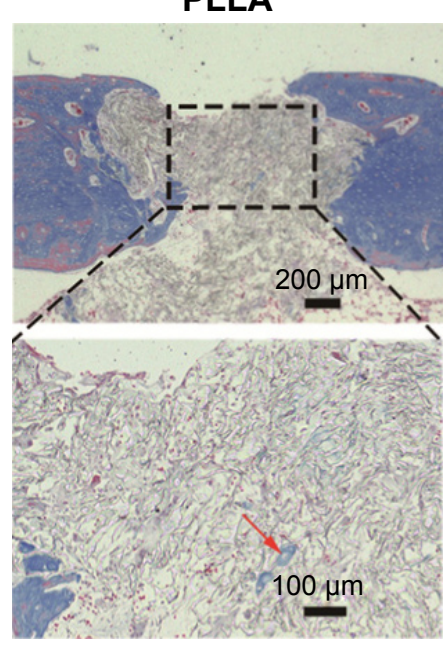

HA/PLLA

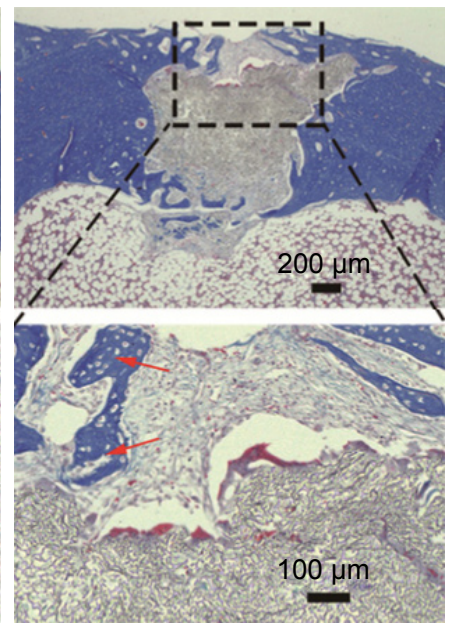

Sr-HA/PLLA

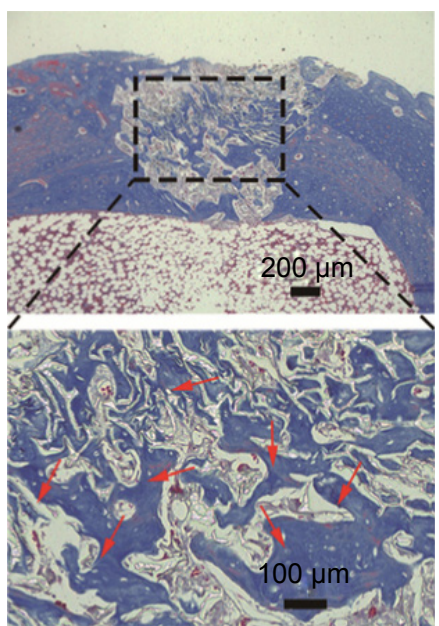

Figure 7 The changes in bone microstructure after implantation of different porous scaffolds.

Notes: (A) Microscopic images of H\&E-stained tissue sections of femur defects after 5 weeks' implantation. (B) Masson-stained tissue sections of femur defects after 5 weeks' implantation (black arrow: new bone, $\wedge$ : blood vessel, and red arrow: collagen).

Abbreviations: H\&E, hematoxylin and eosin; PLLA, poly(L-lactic acid); HA/PLLA, hydroxyapatite on porous poly(L-lactic acid); Sr-HA/PLLA, strontium-doped hydroxyapatite on porous poly(L-lactic acid).

observed in the defect area by the Sr-HA/PLLA porous scaffold treatment (Figure 7A). The vascularization is important to ensure the delivery of nutrients for proliferation of cells in the bone tissue. All of these results suggest the great potential of the Sr-HA/PLLA porous scaffold, and our study may provide a new idea to PLLA materials by biomimetic mineralized Sr-HA porous scaffolds for the repair of bone defects.

\section{Conclusion}

In this study, Sr-HA/PLLA porous scaffold, a novel biomimetic mineralized composite scaffold material, was successfully fabricated. The property of hydrophily, the modulus of compression, and the adsorption of protein were improved. In vivo and vitro experiments confirmed that the Sr-HA/ PLLA porous scaffold had excellent biocompatibility and could promote adhesion and proliferation of MC3T3-E1 cells. The micro-CT and histological results showed that the Sr-HA/PLLA porous scaffold could effectively promote the restoration of bone defects in a rabbit femur defect model (Figure 8). In summary, the results provided reliable evidence that Sr-HA/PLLA may be a prospective strategy for future clinical application in bone tissue engineering.

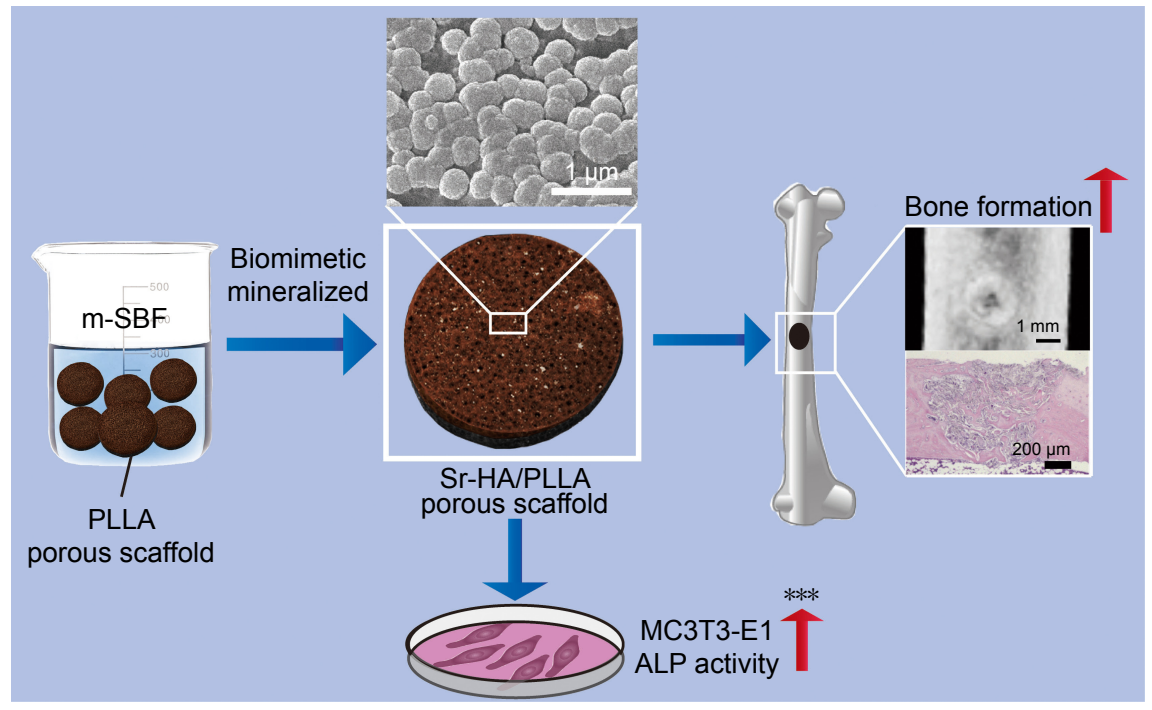

Figure 8 Scheme of the preparation and bone defect repair of the Sr-HA/PLLA porous scaffold.

Note: $* * * P<0.001$.

Abbreviations: Sr-HA/PLLA, strontium-doped hydroxyapatite on porous poly(L-lactic acid); m-SBF, modified simulated body fluid; PLLA, poly(L-lactic acid); MC3T3-EI, mouse preosteoblast cell line. 


\section{Acknowledgment}

This research was supported by the National Natural Science Foundations of China (31470961, 21271059, 21301046, and 51302062), Hebei Province "Hundred Talents Program" (BR2-202), Hebei Province "Three Three Three Talents Program" (A201401002), and Natural Science Foundation of Hebei Province (B2016201209).

\section{Author contributions}

All authors contributed toward data analysis, drafting, and revising the paper, and agreed to be accountable for all aspects of the work.

\section{Disclosure}

The authors report no conflicts of interest in this work.

\section{References}

1. Yang CR. Research process and problem of bone tissue engineering scaffold. Tissue Eng Res. 2009;13(8):1529-1532.

2. Buser D, Belser UC, Lang NP. The original one-stage dental implant system and its clinical application. Periodontol. 1998;17(1):106-118.

3. Yang DH, Lee DW, Kwon YD, et al. Surface modification of titanium with hydroxyapatite-heparin-BMP-2 enhances the efficacy of bone formation and osseointegration in vitro and in vivo. J Tissue Eng Regen Med. 2015;9(9):1067-1077.

4. Bongio M. Development of bone substitute materials: from "biocompatible" to "instructive". J Mater Chem. 2010;20(40):8747-8759.

5. Hao D, Dong YJ, Peng WX. Preparation and characterization of calcium phosphate cement/gelatin composite scaffold for bone tissue engineering. J Funct Mater. 2006;37(11):1805-1894.

6. Dulińska-Molak I, Jaroszewicz J, Kurzydlowski KJ. Architecture and properties of PUR/Calcite composite scaffolds for bone tissue engineering. J Bioproces Biotech. 2014;4(3):1-18.

7. Félix Lanao RP, Jonker AM, Wolke JG, Jansen JA, van Hest JC, Leeuwenburgh SC. Physicochemical properties and applications of poly(lactic-co-glycolic acid) for use in bone regeneration. Tissue Eng Part B Rev. 2013;19(4):380-390.

8. Han Q, He C, Zhao L, et al. Cell adhesion and degradation of a PGA scaffold for tissue engineering. J Pharm Anal. 2013;33(8):1331-1335.

9. Ghasemi-Mobarakeh L, Prabhakaran MP, Morshed M, et al. Biofunctionalized PCL nanofibrous scaffolds for nerve tissue engineering. Mater Sci Eng C. 2010;30(8):1129-1136.

10. Hammouche S, Hammouche D, McNicholas M. Biodegradable bone regeneration synthetic scaffolds: in tissue engineering. Curr Stem Cell Res Ther. 2012;7(2):134-142.

11. Scharber MC, Sariciftci NS. Synthetic biopolymer nanocomposites for tissue engineering scaffolds. Prog Polym Sci. 2013;38(12):1487-1503.

12. Ma PX. Biomimetic materials for tissue engineering. Adv Drug Deliv Rev. 2008;60(2):184-198

13. Alvarez-Barreto JF, Landy B, VanGordon S, Place L, DeAngelis PL, Sikavitsas VI. Enhanced osteoblastic differentiation of mesenchymal stem cells seeded in RGD-functionalized PLLA scaffolds and cultured in a flow perfusion bioreactor. J Tissue Eng Regen Med. 2011;5(6): 464-475.

14. He C, Xiao G, Jin X, Sun C, Ma PX. Electrodeposition on nanofibrous polymer scaffolds: rapid mineralization, tunable calcium phosphate composition and topography. Adv Funct Mater. 2010;20(20):3568-3576.

15. Turco G, Marsich E, Bellomo F, et al. Alginate/hydroxyapatite biocomposite for bone ingrowth: a trabecular structure with high and isotropic connectivity. Biomacromolecules. 2009;10(6):1575-1583.
16. Luo Y, Lode A, Wu C, Chang J, Gelinsky M. Alginate/nanohydroxyapatite scaffolds with designed core/shell structures fabricated by $3 \mathrm{D}$ plotting and in situ mineralization for bone tissue engineering. ACS Appl Mater Interfaces. 2015;7(12):6541-6549.

17. Wang C, Liu D, Zhang C, et al. Defect-related luminescent hydroxyapatite-enhanced osteogenic differentiation of bone mesenchymal stem cells via an ATP-induced cAMP/PKA pathway. ACS Appl Mater Interfaces. 2016;8(18):11262-11271.

18. Brown EM. Is the calcium receptor a molecular target for the actions of strontium on bone? Osteoporos Int. 2003;14(3):25-34.

19. Qiu K, Zhao XJ, Wan CX, et al. Effect of strontium ions on the growth of ROS17/2.8 cells on porous calcium polyphosphate scaffolds. Biomaterials. 2006;27(8):1277-1286.

20. Li L, Lu X, Meng Y, Weyant CM. Comparison study of biomimetic strontium-doped calcium phosphate coatings by electrochemical deposition and air plasma spray: morphology, composition and bioactive performance. J Mater Sci Mater Med. 2012;23(10): 2359-2368.

21. Johal KK, Mendoza-Suárez G, Escalante-García JI, Hill RG, Brook IM. In vivo response of strontium and zinc-based ionomeric cement implants in bone. J Mater Sci-Mater M. 2002;13(4):375-379.

22. Guo D, Xu K, Han Y. The influence of Sr doses on the in vitro, biocompatibility and in vivo, degradability of single-phase Sr-incorporated HAP cement. J Biomed Mater Res A. 2008;86(4):947-958.

23. Tian M, Chen F, Song W, et al. In vivo study of porous strontiumdoped calcium polyphosphate scaffolds for bone substitute applications. J Mater Sci-Mater M. 2009; 20(7):1505-1512.

24. JohnŁ, Podgórska M, Nedelec JM, Cwynar-ZajacŁ, DzięgielP. Strontiumdoped organic-inorganic hybrids towards three-dimensional scaffolds for osteogenic cells. Mat Sci Eng C Mater. 2016;68:117-127.

25. Liu H, Cheng J, Chen F, et al. Biomimetic and cell-mediated mineralization of hydroxyapatite by carrageenan functionalized graphene oxide. ACS Appl Mater Interfaces. 2014;6(5):3132-3140.

26. Barati D, Walters JD, Shariati SR, Moeinzadeh S, Jabbari E. Effect of organic acids on calcium phosphate nucleation and osteogenic differentiation of human mesenchymal stem cells on peptide functionalized nanofibers. Langmuir. 2015;31(18):5130-5140.

27. Ge M, Xue L, Nie T, Ma H, Zhang J. The precision structural regulation of PLLA porous scaffold and its influence on the proliferation and differentiation of MC3T3-E1 cells. J Biomater Sci Polym Ed. 2016;27(17): 1685-1697.

28. Ma H, Xue L, Nie T. Fabrication of PLLA scaffold with gradient macro/ micro/nano structure by electrophoretic deposition of carbon nanotube. Mater Lett. 2015;159:185-188.

29. Liu H, Xi P, Xie G, et al. Simultaneous reduction and surface functionalization of graphene oxide for hydroxyapatite mineralization. J Phys Chem C. 2012;116(5):3334-3341.

30. Woo KM, Chen VJ, Ma PX. Nano-fibrous scaffolding architecture selectively enhances protein adsorption contributing to cell attachment. J Biomed Mater Res A. 2003;67(2):531-537.

31. Quarles LD, Hartle JE 2nd, Siddhanti SR, Guo R, Hinson TK. A distinct cation-sensing mechanism in MC3T3-E1 osteoblasts functionally related to the calcium receptor. J Bone Miner Res. 1997;12(3):393-402.

32. Zhang J, Li Y, Sun J, Liu C, Zhang D. Synergistic or antagonistic effect of MTE plus TF or icariin from epimedium koreanum on the proliferation and differentiation of primary osteoblasts in vitro. Biol Trace Elem Res. 2011;143(3):1746-1757.

33. Lv L, Liu Y, Zhang P, et al. The nanoscale geometry of $\mathrm{TiO} 2$ nanotubes influences the osteogenic differentiation of human adipose-derived stem cells by modulating H3K4 trimethylation. Biomaterials. 2015; 39:193-205.

34. Liu DM, Troczynski T, Tseng WJ. Water-based sol-gel synthesis of hydroxyapatite: process development. Biomaterials. 2001;22(13): 1721-1730.

35. Chaudhry AA, Haque S, Kellici S, et al. Instant nano-hydroxyapatite: a continuous and rapid hydrothermal synthesis. Chem Commun. 2006; 21:2286-2288. 
36. Feng X, Ye J, Wang Y, et al. Deagglomeration of HA during the precipitation synthesis. J Mater Sci. 2005;40(20):5439-5442.

37. Yeung WK, Reilly GC, Matthews A, Yerokhin A. In vitro biological response of plasma electrolytically oxidized and plasma-sprayed hydroxyapatite coatings on Ti-6Al-4V alloy.J Biomed Mater Res B Appl Biomater. 2013;101(6):939-949.

38. Huang J, Liu G, Song C, et al. Role of molecular chemistry of degradable pHEMA hydrogels in three-dimensional biomimetic mineralization. Chem Mater. 2012;24(7):1331-1337.

39. Li Y, Li Q, Zhu S, et al. The effect of strontium-substituted hydroxyapatite coating on implant fixation in ovariectomized rats. Biomaterials. 2010;31(34):9006-9014.

40. Park JW, Kwon TG, Suh JY. The relative effect of surface strontium chemistry and super-hydrophilicity on the early osseointegration of moderately rough titanium surface in the rabbit femur. Clin Oral Implants Res. 2013;24(6):706-709.

41. Liang K, Ricco R, Doherty CM, et al. Biomimetic mineralization of metal-organic frameworks as protective coatings for biomacromolecules. Nat Commun. 2015;6:7240-7248.

42. Fratzl P. Biomimetic materials research: what can we really learn from nature's structural materials? J R Soc Interface. 2007;4(15):637-642.

43. Tan J, Saltzman WM. Biomaterials with hierarchically defined microand nanoscale structure. Biomaterials. 2004;25(17):3593-3601.

44. Chung WJ, Oh JW, Kwak K, et al. Biomimetic self-templating supramolecular structures. Nature. 2011;478(7369):364-368.

45. Cao H, Zhang L, Zheng H, et al. Hydroxyapatite nanocrystals for biomedical applications. J Phys Chem C. 2010;114(43):18352-18357.

46. Depan D, Girase B, Shah JS, Misra RD. Structure-process-property relationship of the polar graphene oxide-mediated cellular response and stimulated growth of osteoblasts on hybrid chitosan network structure nanocomposite scaffolds. Acta Biomater. 2011;7(9):3432-3445.

47. Pramanik N, Imae T. Fabrication and characterization of dendrimerfunctionalized mesoporous hydroxyapatite. Langmuir. 2012;28(39) 14018-14027.

48. Zhu H, Guo D, Qi W, Xu K. Development of Sr-incorporated biphasic calcium phosphate bone cement. Biomed Mater. 2017;12(1):015016.

49. Jongpaiboonkit L, Franklinford T, Murphy WL. Growth of hydroxyapatite coatings on biodegradable polymer microspheres. ACS Appl Mater Interfaces. 2009;1(7):1504-1511.

50. Ju YM, Park K, Son JS, Kim JJ, Rhie JW, Han DK. Beneficial effect of hydrophilized porous polymer scaffolds in tissue-engineered cartilage formation. J Biomed Mater Res B Appl Biomater. 2008;85(1): 252-260.

51. Ma Z, Gao C, Gong Y, Shen J. Chondrocyte behaviors on poly-1-lactic acid (PLLA) membranes containing hydroxyl, amide or carboxyl groups. Biomaterials. 2003;24(21):3725-3730.

52. Hutmacher DW. Scaffolds in tissue engineering bone and cartilage. Biomaterials. 2000;21(24):2529-2543.

53. Yan LP, Correia JS, Oliveira MB, et al. Bilayered silk/silk-nanoCaP scaffolds for osteochondral tissue engineering: in vitro and in vivo assessment of biological performance. Acta Biomater. 2015;12:227-241.
54. Liu W, Yeh YC, Lipner J, et al. Enhancing the stiffness of electrospun nanofiber scaffolds with a controlled surface coating and mineralization. Langmuir. 2011;27(15):9088-9093.

55. Lih E, Park KW, Chun SY, et al. Biomimetic porous PLGA scaffolds incorporating decellularized extracellular matrix for kidney tissue regeneration. ACS Appl Mater Interfaces. 2016;8(33):21145-21154.

56. Wang X, Xu S, Zhou S, et al. Topological design and additive manufacturing of porous metals for bone scaffolds and orthopaedic implants: a review. Biomaterials. 2016;83:127.

57. Chen H, Yuan L, Song W, et al. Biocompatible polymer materials: role of protein-surface interactions. Prog Polym Sci. 2008;33(11): 1059-1087.

58. Yang J, Cao X, Zhao Y, et al. Enhanced pH stability, cell viability and reduced degradation rate of poly(L-lactide)-based composite in vitro: effect of modified magnesium oxide nanoparticles. J Biomater $S \mathrm{Si}$ Polym Ed. 2017;28(5):486-503.

59. Suganuma J, Alexander H. Biological response of intramedullary bone to poly-L-lactic acid. $J$ Appl Biomater. 1993;4(1):13-27.

60. Tomecka E, Wojasinski M, Jastrzebska E, Chudy M, Ciach T, Brzozka Z. Poly(l-lactic acid) and polyurethane nanofibers fabricated by solution blow spinning as potential substrates for cardiac cell culture. Mater Sci Eng C Mater Biol Appl. 2017;75:305-316.

61. Li X, Sun H, Lin N, et al. Regeneration of uterine horns in rats by collagen scaffolds loaded with collagen-binding human basic fibroblast growth factor. Biomaterials. 2011;32(32):8172-8181.

62. Kokubo T, Kim HM, Kawashita M. Novel bioactive materials with different mechanical properties. Biomaterials. 2003;24(13):2161-2175.

63. Gao X, Song J, Ji P, et al. Polydopamine-templated hydroxyapatite reinforced polycaprolactone composite nanofibers with enhanced cytocompatibility and osteogenesis for bone tissue engineering. ACS Appl Mater Interfaces. 2016;8(5):3499-3515.

64. Harris MT, Butler DL, Boivin GP, Florer JB, Schantz EJ, Wenstrup RJ. Mesenchymal stem cells used for rabbit tendon repair can form ectopic bone and express alkaline phosphatase activity in constructs. J Orthop Res. 2004;22(5):998-1003.

65. Liu J, Someren E, Mentink A, et al. The effect of PKC activation and inhibition on osteogenic differentiation of human mesenchymal stem cells. J Tissue Eng Regen Med. 2010;4(5):329-339.

66. Harris JD, Siston RX, Flanigan DC. Autologous chondrocyte implantation: a systematic review. Osteoarthritis Cartilage. 2006; 14(1):47-51.

67. Bouyer M, Guillot R, Lavaud J, et al. Surface delivery of tunable doses of BMP-2 from an adaptable polymeric scaffold induces volumetric bone regeneration. Biomaterials. 2016;104:168-181.

68. Yang F, Yang D, Tu J, Zheng Q, Cai L, Wang L. Strontium enhances osteogenic differentiation of mesenchymal stem cells and in vivo bone formation by activating Wnt/catenin signaling. Stem Cells. 2011;29(6): 981-991.

69. Wei G, Ma PX. Macroporous and nanofibrous polymer scaffolds and polymer/bone-like apatite composite scaffolds generated by sugar spheres. J Biomed Mater Res A. 2010;78(2):306-315. 


\section{Supplementary materials Methods}

Poly(L-lactic acid) (PLLA) with an inherent viscosity of $1.6 \mathrm{dL} / \mathrm{g}$ was purchased from Ji'nan Daigang (Ji Nan, China). D-fructose (melting point [m.p.] $119^{\circ} \mathrm{C}-122^{\circ} \mathrm{C}$ ) and Span 80 were purchased from Sigma-Aldrich Co (St Louis, MO, USA). Dioxane, cyclohexane, and hexane were purchased from Sigma-Aldrich Co.

\section{Preparation of PLLA porous scaffolds}

The PLLA porous scaffolds were fabricated according to our previous work. The details were reported. ${ }^{1}$ Briefly, D-fructose was melted and then emulsified into mineral oil with Span 80 as a surfactant under stirring. The resulting mixture was cooled down, and the sugar spheres were washed and sieved to desired sizes. The sieved sugar spheres were packed and heated to form a template. PLLA/dioxane solution was casted into the assembled sugar template under vacuum. The above system was phase separated at $-20^{\circ} \mathrm{C}$ overnight. The resulting composites were freeze-dried, the sugar was leached out in distilled water, and then the scaffold was freeze-dried.

\section{Subcutaneous implantation of the porous scaffolds}

Twenty ICR mice were used for biocompatibility in vivo. The mice were anesthetized by chloral hydrate, and a $10 \mathrm{~mm}$ long skin incision was made in the back of the mice. After that, the scaffolds were placed subcutaneously. Mice were sacrificed with ether after 30 days of surgery. The scaffolds, together with surrounding tissues, were excised and immediately fixed in $10 \%$ formalin solution.
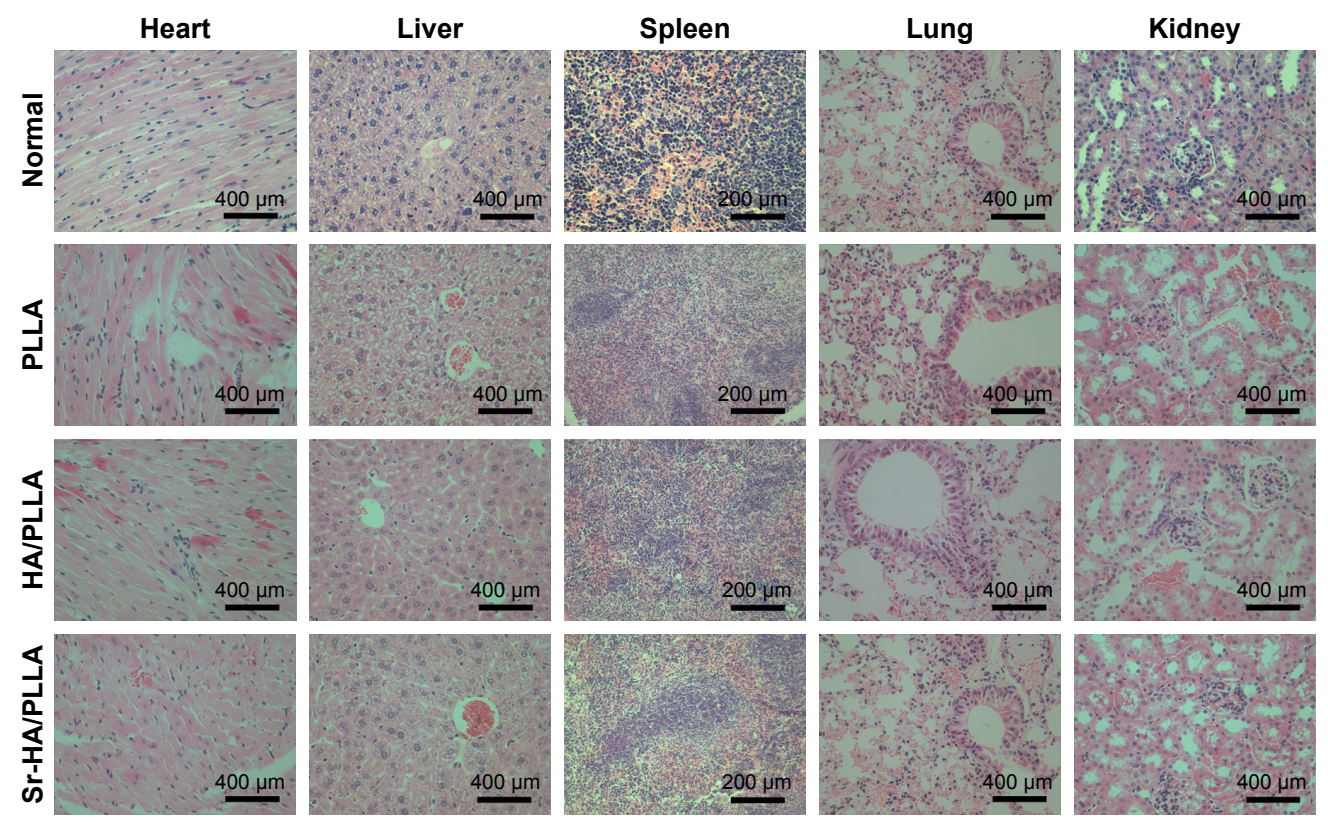

Figure SI Histopathology of the heart, liver, spleen, lung, and kidney of mice.

Abbreviations: PLLA, poly(L-lactic acid); HA/PLLA, hydroxyapatite on porous poly(L-lactic acid); Sr-HA/PLLA, strontium-doped hydroxyapatite on porous poly(L-lactic acid). 


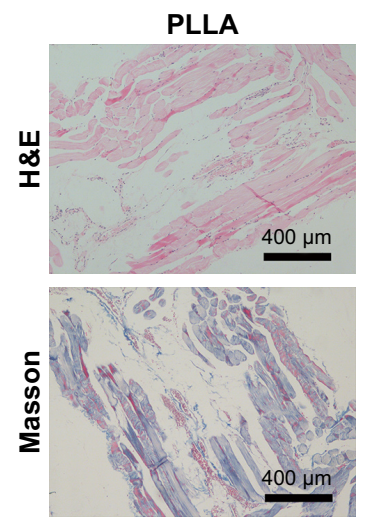

HA/PLLA
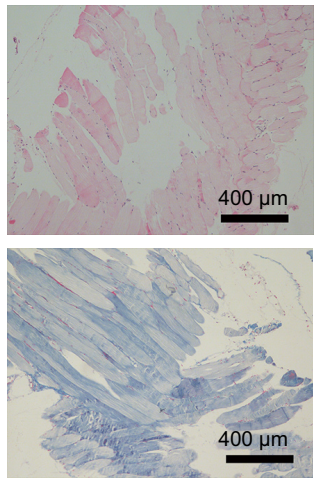

Sr-HA/PLLA

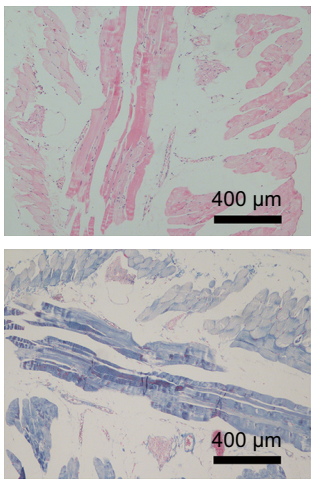

Figure S2 Histological images of scaffolds and surrounding tissue in mice stained with H\&E and Masson.

Abbreviations: H\&E, hematoxylin and eosin; PLLA, poly(L-lactic acid); HA/PLLA, hydroxyapatite on porous poly(L-lactic acid); Sr-HA/PLLA, strontium-doped hydroxyapatite on porous poly(L-lactic acid).

\section{Reference}

1. Ge M, Xue L, Nie T, Ma H, Zhang J. The precision structural regulation of PLLA porous scaffold and its influence on the proliferation and differentiation of MC3T3-E1 cells. J Biomater Sci Polym Ed. 2016;27(17): $1685-1697$.

\section{Publish your work in this journal}

The International Journal of Nanomedicine is an international, peerreviewed journal focusing on the application of nanotechnology in diagnostics, therapeutics, and drug delivery systems throughout the biomedical field. This journal is indexed on PubMed Central, MedLine, CAS, SciSearch $®$, Current Contents $₫ /$ Clinical Medicine,
Journal Citation Reports/Science Edition, EMBase, Scopus and the Elsevier Bibliographic databases. The manuscript management system is completely online and includes a very quick and fair peer-review system, which is all easy to use. Visit http://www.dovepress.com/ testimonials.php to read real quotes from published authors.

\footnotetext{
Submit your manuscript here: http://www.dovepress.com/international-journal-of-nanomedicine-journal
} 